\begin{tabular}{|c|l|}
\hline Title & $\begin{array}{l}\text { A symmetric hydrogenation of 1-phenyletheny lboronic acid and esters for the synthesis of chiral organoboron } \\
\text { compounds }\end{array}$ \\
\hline Author(s) & Ueda, Masato; Saitoh, A tsushi; Miy aura, Norio \\
\hline Citation & $\begin{array}{l}\text { Journal of Organometallic Chemistry, 642(1-2), 145-147 } \\
\text { https://doi.org/10.1016/S0022-328X (01)01239-6 }\end{array}$ \\
\hline Issue Date & 2002-01-18 \\
\hline Doc URL & http://hdl.handle.net/2115/15837 \\
\hline Type & article (author version) \\
\hline File Information & JOc642-1-2.pdf \\
\hline
\end{tabular}

Instructions for use 


\title{
Asymmetric Hydrogenation of 1-Phenylethenylboronic Acid and Esters for the Synthesis of Chiral Organoboron Compounds
}

\author{
Masato Ueda, Atsushi Saitoh, and Norio Miyaura* \\ Division of Molecular Chemistry, Graduate School of Engineering, Hokkaido University, \\ Sapporo 060-8628, Japan
}

\begin{abstract}
The hydrogenation of ethanediol 1-phenylethenylboronic ester was carried out at $-20{ }^{\circ} \mathrm{C}$ under the atmosphere of hydrogen $(9$ atms) in the presence of [Rh(cod) $\left.)_{2}\right] \mathrm{BF}_{4} /(\mathrm{R})$-BINAP (3 mol\%). After alkaline hydrogen peroxide oxidation, the reaction gave 1-phenylethanol with $80 \%$ ee.
\end{abstract}

\section{$1 \quad$ Introduction}

Chiral organoboron compounds [1] are available from the hydroboration of internal alkenes with chiral hydroboration reagents including di(isopinocampheyl)borane [2], mono-isopinocampheylborane [2], and 2,5-dimethylboronane [3]. The discovery of the intramolecular $\mathrm{S}_{\mathrm{N}} 2$ substitution reaction of chiral ( $\alpha$-haloalkyl)boronic esters with carbon- or hetero-nucleophiles has resulted in an additional and practical method of broad scope [4]. Although such synthesis using a 
stoichiometric chiral auxiliary has its own excellence, the catalyzed hydroboration of alkenes with metal-chiral phosphine complexes significantly overcame the limitations of the cost/availability of the chiral borane reagents [5]. On the other hand, the asymmetric hydrogenation of prochiral functionalized alkenes with a metal-chiral phosphine complex is a promising and reliable method for the synthesis of optically active compounds, which has not yet been studied in regard to 1-alkenylboron compounds [6]. Here, we wish to report the preliminary results for the asymmetric hydrogenation of 1-phenylethenylboronic acid and its esters (1) with a rhodium/chiral phosphine complex (Scheme 1). A combination of [Rh(cod $\left.)_{2}\right] \mathrm{BF}_{4}$ and BINAP [7] was found to be most effective to achieve high enantioselectivity for ethanediol 1-phenylethenylboronic ester (1b), which was first synthesized by resolution of the bisdemethylbrucine derivative [8] and was recently studied extensively by the catalyzed hydroboration of styrene with catecholborane [5].

$$
<<\text { Scheme } 1>>
$$

\section{$2 \quad$ Results and Discussion}

Hydrogenation of $\mathbf{1}$ with a rhodium-chiral phosphine complex was carried out at room temperature under the atmosphere of hydrogen (9 atms). After the alkaline $\mathrm{H}_{2} \mathrm{O}_{2}$ oxidation of 2a-d, 1-phenylethanol $\mathbf{3}$ was analyzed by a chiral stationary column (Dicel Chiralcel OD-H) to evaluate the enantioselectivities of 2. High enantioselectivity up to $80 \%$ ee was often observed in ethanol or isopropanol, but the reactions in alcohols suffered from low yields due to the C-B bond cleavage of 2 giving ethylbenzene 
because of the sensitivity of benzylboronates to the hydrolytic protodeboronation with alcohols. Thus, the reactions in aprotic solvents afforded good yields of $\mathbf{3}$, though the catalytic hydrogenolysis of the C-B bond still provided some ethylbenzene $(<10 \%)$ [9]. Nonpolar solvents having a high solubility of the catalyst such as $\mathrm{CH}_{2} \mathrm{Cl}_{2}$ or 1,2-dichloroethane revealed higher enantioselectivity than donating solvents. The effect of solvents on enantioselectivity was observed as follows for the hydrogenation of $\mathbf{1 b}$ with a $\quad\left[\mathrm{Rh}(\mathrm{cod})(\mathrm{MeCN})_{2}\right] \mathrm{BF}_{4} /(\mathrm{R})$-BINAP catalyst: $\quad \mathrm{CH}_{2} \mathrm{Cl}_{2} \quad$ (S-3, 64\%ee), 1,2-dichloroethane (S-3, 65\%еe), dimethoxyethane (S-3, 46\%еe), THF (S-3, 43\%еe), acetone (S-3, 31\%ee), and DMF (R-3, 12\%еe). DMF reversed the absolute configuration of $\mathbf{3}$ presumably due to the coordination of the solvent to the rhodium metal center because the neutral rhodium complexes such as $[\mathrm{Rh}(\mathrm{cod}) \mathrm{Cl}]_{2} / 2(\mathrm{R})$-BINAP also yielded R-3 (46\% yield, 21\%ee). On the other hand, the hydrogen pressure did not change the enantioselectivity of $\mathbf{3}$ in a range of 1 to 20 atms [7b].

The hydrogenation of $\mathbf{1}$ with a $\left[\mathrm{Rh}(\mathrm{cod})_{2}\right] \mathrm{BF}_{4} /$ chiral phosphine catalyst is summarized in Table 1, wherein less effort was directed to optimization of chemical yields.

$$
<<\text { Table } 1>>
$$

A screening of the representative chiral ligands revealed the efficiency of BINAP (entries 1-4). The reaction employed (R)-BINAP gave 1-phenylethanol with 65\%ee at room temperature. The enantioselectivity was strongly dependent on the reaction temperature, higher selectivity being observed at lower temperature. Although 
the hydrogenation was slow at lower than $0{ }^{\circ} \mathrm{C}$, the enantioselectivity was improved to $80 \%$ ee at $-20{ }^{\circ} \mathrm{C}$ (entry 5). The catalyst was in situ prepared from $\left[\mathrm{Rh}(\mathrm{cod})_{2}\right] \mathrm{BF}_{4}$ and a chiral phosphine, but the isolated $[\mathrm{Rh}(\mathrm{R}-\mathrm{BINAP})] \mathrm{BF}_{4}$ revealed essentially the same enantioselectivity. The selectivity can be controlled by the steric factor between the phenyl and boryl groups because the 1,3-propanediol ester 1c resulted in a slightly lower enantioselectivity than that of $\mathbf{1 b}$ (entry 7) and the pinacol ester $\mathbf{1 d}$ reversed the absolute configuration due to the greater bulkiness of the boryl ring than that of the phenyl ring (entry 8).

Further studies are in progress to elucidate the hydrogenation of other 1-alkenylboronates and the possible synthetic applications.

\section{Experimental}

\subsection{Material and reagents}

Hydrogenation was carried out in a thick-walled glass bottle fitted with a Young valve. (R,R)-DIOP, (R,R)-CHIRAPHOS, (S,S)-Me-DuPHOS, and (R)-BINAP were purchased from AZmax. $\left[\mathrm{Rh}(\mathrm{cod})_{2}\right] \mathrm{BF}_{4}$ was prepared by the reported procedure $[10]$

\subsection{1-Phenylethenylboronic esters (1) [8]}

To a 500 ml-flask charged with magnesium turnings (1.46 g, $60 \mathrm{mmol})$ and THF (100 ml) were dropwise added 1,2-dibromoethane $(0.8 \mathrm{ml})$ followed by $\alpha$-bromostyrene (9.15 g, $50 \mathrm{mmol}$ ) in THF (80 ml). After being stirred for $30 \mathrm{~min}$ at 
$80{ }^{\circ} \mathrm{C}$, the mixture was cooled to $-78{ }^{\circ} \mathrm{C}$. A solution of $\mathrm{B}(\mathrm{OMe})_{3}(5.6 \mathrm{ml})$ in THF (80 $\mathrm{ml}$ ) was dropwise added over $1 \mathrm{~h}$ to the Grignard solution. The resulting mixture was stirred for $1 \mathrm{~h}$ at $-78{ }^{\circ} \mathrm{C}$ and overnight at room temperature, and was then treated with aqueous $6 \mathrm{M} \mathrm{HCl}(50 \mathrm{ml})$. The mixture was extracted with ether and washed with water, and all volatile matters were evaporated in vacuo to give a crude solid of 1-phenylethenylboronic acid. The solid was dissolved in toluene (50 ml) and treated with 1,3-propanediol (5.4 ml, $75 \mathrm{mmol}$ ) and $\mathrm{MgSO}_{4}$ (3 g) at room temperature overnight. After filtration of the drier, the filtrate was washed with water to remove the excess diol (30 ml x 3) and dried again over $\mathrm{MgSO}_{4}$. Distillation under reduced pressure gave 2-(1-phenylethenyl)-1,3,2-dioxaborinane (1c). Yield 6.27 g (66\%); bp $157{ }^{\circ} \mathrm{C} / 14$ $\mathrm{mmHg}$.

2-(1-Phenylethenyl)-1,3,2-dioxaborolane (1a, bp $70 \quad{ }^{\circ} \mathrm{C} / 0.5 \mathrm{mmHg}$ ) was prepared by the above general procedure from 1,2-ethanediol. 2-(1-Phenylethenyl)-4,4,5,5-tetramethyl-1,3,2-dioxaborolane (1d) was isolated by chromatography over silica gel with hexane/toluene (10/1).

\subsection{Representative procedure}

A mixture of $\left[\mathrm{Rh}(\mathrm{cod})_{2}\right] \mathrm{BF}_{4}(0.03 \mathrm{mmol}),(\mathrm{R})-(+)-\mathrm{BINAP}(0.036 \mathrm{mmol})$, and ethanediol 1-phenylethenyl-boronic ester 1b [8] (1.0 mmol) in 1,2-dichloroethane (6 $\mathrm{ml}$ ) was stirred for $30 \mathrm{~min}$ in a glass pressure bottle. After being cooled to $-20{ }^{\circ} \mathrm{C}$, hydrogen was introduced from the gas cylinder and was then discarded in vacuo (10 mmHg). After three repetitions, the bottle was pressured to 9 atms. The resulting 
mixture was stirred for 7 days at $-20{ }^{\circ} \mathrm{C}$. $3 \mathrm{M} \mathrm{NaOAc}(1 \mathrm{ml})$ and $30 \% \mathrm{H}_{2} \mathrm{O}_{2}(1 \mathrm{ml})$ were added. After being stirred for $2 \mathrm{~h}$ at room temperature, 1-phenylethanol was isolated by chromatography over silica gel with hexane/ether=10/1 in 65\% yield. HPLC analysis using a chiral stationary column (Dicel Chiralcel OD-H) revealed 80\%еe $\left([\alpha]_{\mathrm{D}}{ }^{20}-31.9\right.$ (c 1.00, EtOH). The absolute configuration was established to the S-form by the rotation of an authentic sample, $[\alpha]_{\mathrm{D}}^{20}+41.7$ (c 1.00, EtOH) [11].

\section{References}

[1] For representative reviews, see: (a) D.S. Matteson, Stereodirected Synthesis with Organoboranes, Springer, Berlin, 1995. (b) A. Pelter, K. Smith, H.C. Brown, Borane Reagents; Academic, New York, 1988. (c) I. Beleskaya, A. Pelter, Tetrahedron, 53 (1997) 4957.

[2] H.C. Brown, B. Singaram, Acc. Chem. Res. 21 (1988) 287.

[3] S. Masamune, B.M. Kim, J.S. Petersen, T. Sato, S.J. Veenstra, T. Imai, J. Am. Chem. Soc. 107 (1985) 4549.

[4] (a) D.S. Matteson, Chem. Rev. 89 (1989) 1535. (b) D.S. Matteson, Synthesis (1986), 973.

[5] (a) T. Hayashi, Y. Matsumoto, Y. Ito, J. Am. Chem. Soc. 111 (1989) 3426. (b) J.M. Brown, D.I. Hulmes, T..P. Layzell, J. Chem. Soc. Chem. Commun. (1993), 1673. (c) K. Burgess, M.J. Ohlmeyer, K.H. Whitmire, Organometallics, 11 (1992) 3588. (d) H.C.L. Abbenhuis, U. Burckhardt, V. Gramlich, A. Martelletti, J. Spencer, I. Steiner, A. Togni, Organometallics, 15 (1996) 1614. For a review, see: (e) K. 
Burgess, M.J. Ohlmeyer, Chem. Rev. 91 (1991) 1179.

[6] (a) J.M. Brown, R.L. Halterman, In Comprehensive Asymmetric Catalysis; E.N. Jacobsen, A. Pfaltz, H. Yamamoto (Eds), Springer, Berlin, 1999; Vol 1, pp. 121-198. (b) R. Noyori, Asymmetric Catalysis in Organic Synthesis, John Wiley and Sons: New York, 1994.

[7] (a) H. Takaya,T. Ohta, N. Sayo, H. Kumobayashi, S. Akutagawa, S. Inoue, I. Kasahara, R. Noyori, J. Am. Chem. Soc. 109 (1987) 1596 and 4129. (b) M. Kitamura, Yi. Hisao, M. Ohta, M. Tsukamoto, T. Ohta, H. Takaya, R. Noyori, J. Org. Chem. (1994) 297. (c) H. Takaya, K. Mashima, K. Koyano, M. Yagi, H. Kumobayashi, T. Taketomi, S. Akutagawa, R. Noyori, J. Org. Chem. 51 (1986) 629 and references cited theirin. Hydrogenation of non-functionalized C-C double bond, see: (d) T. Ohta, H. Ikegami, T. Miyake, H. Takaya, J. Organomet. Chem. 502 (1995) 169.

[8] D.S. Matteson, R.A. Bowie, J. Am. Chem. Soc. 87 (1965) 2587.

[9] The metal-catalyzed hydrogenation of 1-alkynyl-, 1-alkenyl-, and alkylboron compounds; see: (a) M. Srebnik, N.B. Bhat, H.C. Brown, Tetrahedron Lett. 29 (1988) 2635. (b) R.L. Lestsinger, I.H. Skoog, J. Org. Chem. 18 (1953) 895. (c) R. Köster, Angew. Chem. 68 (1956) 383.

[10] M. Green, T.A. Kuc, S.H. Taylor, J. Chem. Soc. (A) (1971), 2334.

[11] (R)-(+)-1-Phenylethanol (>99\%) purchased from Aldrich. See also references 5 and 8. 


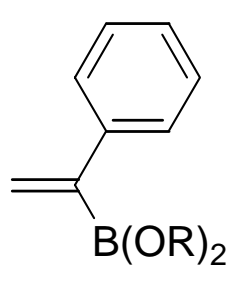

$$
\underset{\begin{array}{c}
\text { Rh catalyst } \\
\text { /chiral ligand }
\end{array}}{\stackrel{\mathrm{H}_{2}}{\longrightarrow}}
$$
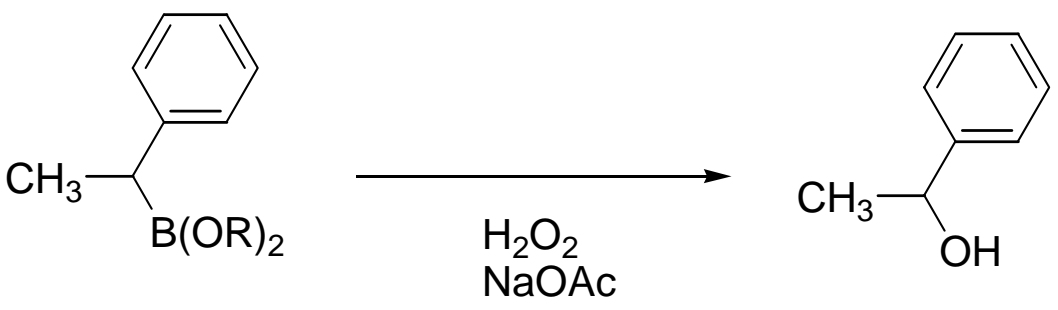

1a: $(\mathrm{OR})_{2}=(\mathrm{OH})_{2}$

2a-d

1b: $(\mathrm{OR})_{2}=-\mathrm{OCH}_{2} \mathrm{CH}_{2} \mathrm{O}-$

1c: $(\mathrm{OR})_{2}=-\mathrm{OCH}_{2} \mathrm{CH}_{2} \mathrm{CH}_{2} \mathrm{O}-$

1d: $(\mathrm{OR})_{2}=-\mathrm{OCMe}_{2} \mathrm{CMe}_{2} \mathrm{O}-$

Scheme 1. Asymmetric Hydrogenation of 1-Phenylethenylboronic Acid and Esters 
Table 1. Asymmetric Hydrogenation of 1-Phenylethenylboronic Acid and Esters $^{a}$<smiles>Pc1cccc(-c2ccccc2)c1P</smiles>

(R)-BINAP<smiles>CC1(C)OC(P)C(c2ccccc2)O1</smiles>

$(R, R)$-DIOP<smiles>CC1=C2[C@H](CC1)C1C(C)CC[C@H]1C[C@@H]1CC[C@H](C)P21</smiles>

(S,S)-Me-DuPHOS<smiles>CC(Pc1ccccc1)C(C)c1ccccc1</smiles>

$(\mathrm{R}, \mathrm{R})$-CHIRAPHOS

\begin{tabular}{cclccc}
\hline entry & $\mathbf{1}$ & ligand & temp $^{\circ}{ }^{\circ} \mathrm{C}$ & yield/\% & \%ee \\
\hline 1 & $\mathbf{1 b}$ & $(\mathrm{R}, \mathrm{R})$-DIOP & 20 & 72 & $19(\mathrm{R})$ \\
2 & & $(\mathrm{R}, \mathrm{R})-\mathrm{CHIRAPHOS}$ & 20 & 4 & $16(\mathrm{~S})$ \\
3 & & $(\mathrm{~S}, \mathrm{~S})-\mathrm{Me}-\mathrm{DuPHOS}$ & 20 & 49 & $42(\mathrm{R})$ \\
4 & & (R)-BINAP & 20 & 75 & $61(\mathrm{~S})$ \\
5 & & (R)-BINAP & -20 & $65^{c}$ & $80(\mathrm{~S})$ \\
6 & $\mathbf{1 a}$ & (R)-BINAP & 20 & 25 & $25(\mathrm{~S})$ \\
7 & $\mathbf{1 c}$ & (R)-BINAP & 20 & 77 & $53(\mathrm{~S})$ \\
8 & $\mathbf{1 d}$ & (R)-BINAP & 20 & 92 & $33(\mathrm{R})$ \\
\hline
\end{tabular}

${ }^{a} \mathrm{~A}$ mixture of $\left[\mathrm{Rh}(\mathrm{cod})_{2}\right] \mathrm{BF}_{4}(0.03 \mathrm{mmol})$, (R,R)-DIOP (0.036 mmol), 1 (1 $\mathrm{mmol}$ ) in 1,2-dichloroethane was stirred for $24 \mathrm{~h}$ under atomospher of $\mathrm{H}_{2}$ (9 atm). The alkaline hydrogenperoxide oxidation gave 1-phenylethanol. ${ }^{b}$ Isolated yields of 1-phenylethanol.

${ }^{c}$ The reaction was carried out for 7 days. 